\title{
DESGASTE DE RODAS E TRILHOS EM PONTES ROLANTES DE LAMINAÇÕES*
}

Andrew Salach ${ }^{1}$ Frank Petrek ${ }^{2}$

\section{Resumo}

Experimento laboratorial avalia desgaste em rodas e trilhos de PR's. Chegou-se a conclusão de que rodas com elevada dureza economizam desgaste de rodas e de trilhos.

Palavras-chave: Rodas e trilhos.

\author{
SURFACE WEAR ON OVERHEAD CRANE WHEELS AND RAILS \\ Abstract \\ Lab experiment has made the wear evaluation of overhead crane wheels and rails. \\ The conclusion pointed that hard wheels save wearing For both, track wheels and \\ rails. \\ Keywords: Wheels and rails.
}




\section{INTRODUÇÃO}

Algumas pontes rolantes fazem parte do processo produtivo em laminações de planos ou de produtos longos - no carregamento de fornos de reaquecimento, ou na retirada de produtos acabados, por exemplo. Reduzir as paradas dessas pontes significa aumentar a disponibilidade produtiva da linha. Um LTQ de capacidade 4 Mt/ano, que pare por uma hora, deixa de faturar $R \$ 820 \mathrm{k}$, aos preços atuais de mercado [1].

Estudo anterior da AIST - Association for Iron \& Steel Technology - mostrou que $43 \%$ das paradas de potes rolantes se devem a problemas nos conjuntos rodeiros. $E$ que dentro desse rubro, $39 \%$ são devidos a desgaste ou quebras de flanges das rodas, como mostram as figuras $1 \& 2$. A figura 3 ilustra o problema.

Programa com elementos finitos, simula a distribuição de cargas nas superfícies de rodas e trilhos, e evidencia as zonas de concentração de tensões (figura 4), que impulsionarão mecanismos de desgaste adesivo (flange), quebra (flange), e fadiga de contato (pista de rolamento).

Propagação frágil de fratura nos flanges e' resultado de perfil inadequado de dureza nas abas das rodas de alta dureza, associado a esforços decorrentes de desalinhamento. Lascamento na pista de rolamento e' típico de rodas com fina camada temperada ou recuperadas por solda, onde a concentração de tensões subsuperficiais ultrapassa limite de escoamento do material da roda. Diferentes perfis de trilhos suportam cargas, de maneira distinta, como mostra a figura 5 , para dois tipos de rodas. O presente trabalho analisa o desgaste de flanges.

\section{TESTES DE LABORATÓRIO}

Há varias especificações de rodas e trilhos, mais ou menos ligados, mais ou menos duros. Trabalho anterior indica que o coeficiente de atrito pode variar em ate' $40 \%$ com a escolha adequada de rodas e trilhos duros [2]. As figuras 6 e 7 mostram opções de materiais de rodas e trilhos, de onde foram tirados corpos de prova para ensaios laboratoriais.

O Battelle Institute, de Columbus - $\mathrm{OH}$, que congrega 7500 pesquisadores, em 4 laboratórios nos EUA, tem apoio de cerca de 2000 empresas privadas e estatais. Registra de 50 a 100 patentes por ano. A pedido da Xtek Inc, fabricante de rodas industriais, avaliou a quantidade de desgaste em rodas e trilhos nos materiais selecionados, de acordo com os pares formados: roda mole com trilho mole, e roda dura com o mesmo trilho mole.

Em dispositivo mostrado esquematicamente na figura 8, esses pares de materiais foram submetidos a 10 mil ciclos de contatos abrasivos, sob pressão controlada, a seco, na temperatura ambiente.

Os corpos de prova de rodas e trilhos, mostrados na figura 9, apresentaram sulcos de desgaste gradualmente crescentes até o final dos testes. Medições do desgaste foram sendo tomadas ao longo dos testes.

\section{RESULTADOS E DISCUSSÃO}

Os resultados são mostrados nas figuras 10 (comparação do desgaste entre rodas mole e dura) e 11 (comparação do desgaste do trilho mole, que trabalhou nas duas situações, com uma ou outra roda). Quando rodas moles são utilizadas, tanto as 
rodas como os trilhos se desgastam mais, 20-30 vezes mais, do que quando rodas duras são usadas. Figura 12 tabula os mesmos dados de outra maneira.

Entre as opções industriais de se obter rodas de dureza elevada (58-62 HRc), materiais e tratamentos térmicos se combinam, como se vê na figura 13. Materiais muito ligados submetidos a temperas severas, podem produzir camadas endurecidas muito profundas, que fragilizam os flanges. Cementação costuma gerar camadas de pouca profundidade de tempera, suscetíveis a fadiga de contato e esfoliamento na pista. Mas vale lembrar que quebras e lascamentos não foram objeto desse trabalho.

\section{COMENTÁRIO FINAL}

Nas laminações brasileiras, nesses 25 anos de acompanhamento de PR's, a pratica tem mostrado que rodas duras $(58-62 \mathrm{HRc})$ rendem no mínimo 4 vezes mais do que rodas de $300 \mathrm{HB}$, e no mínimo 2 vezes mais do que rodas de $450 \mathrm{HB}$. A distância entre os testes de laboratório aqui apresentados e a realidade, indica que outros fatores influem na performance de rodas e trilhos.

\section{Figuras}

\section{Crane Maintenance Spending Survey Results From AIST Crane Symposium}

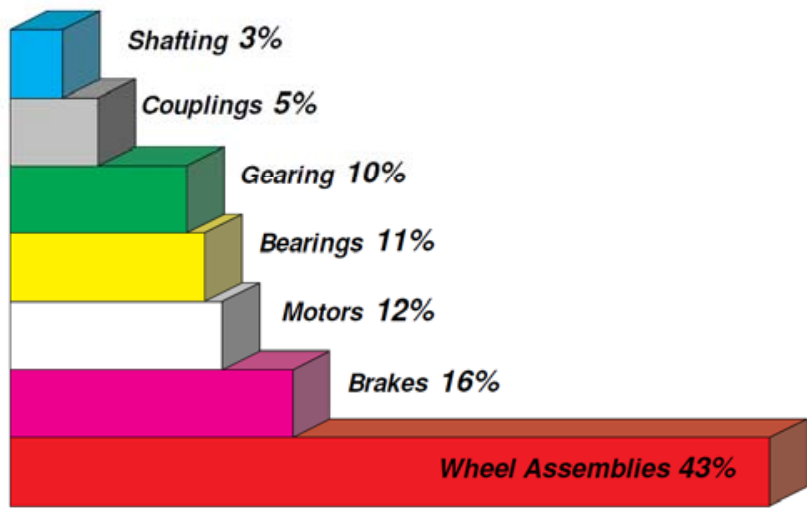

Figura 1 - Causas de parada de pontes rolantes

\section{Wheel Assembly Reasons for Replacement} Survey Results From AIST Crane Symposium

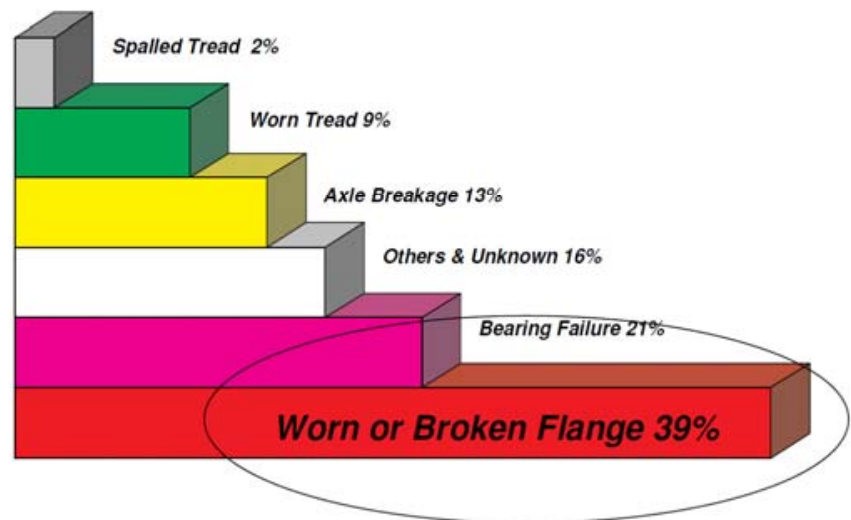

Figura 2 - Causas de reparos de conjuntos rodeiros 


\section{Typical Flange Failures}
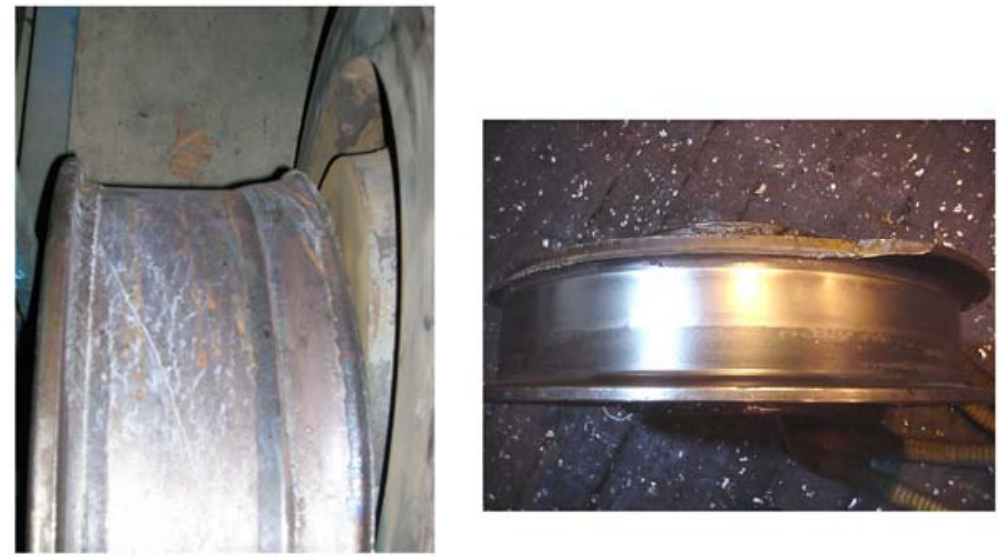

Figura 3 - Desgaste ou quebra de flanges (= abas) de rodas

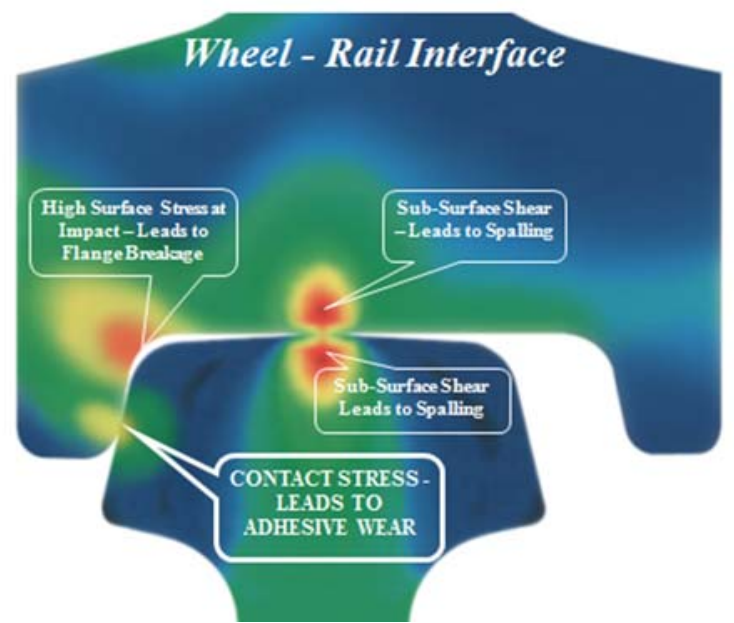

Figura 4 - Zonas de concentracao de tensoes

\section{Allowable Wheel Loads}

(24" Wheel Diameter)

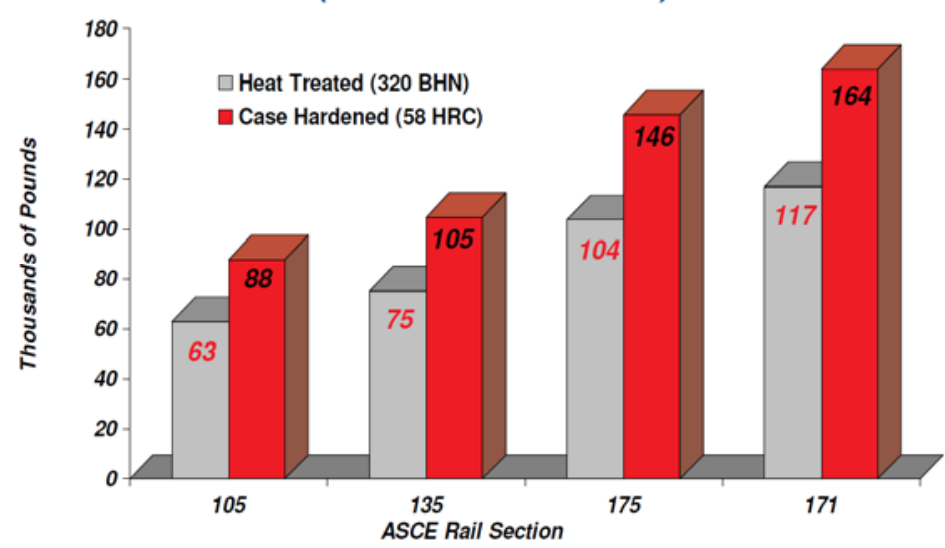

RESULT: 40\% INCREASE IN CAPACITY

Figura 5 - Capacidade de carga de trilhos 


\section{Wheel Test Samples}

v. Wheel Hardness

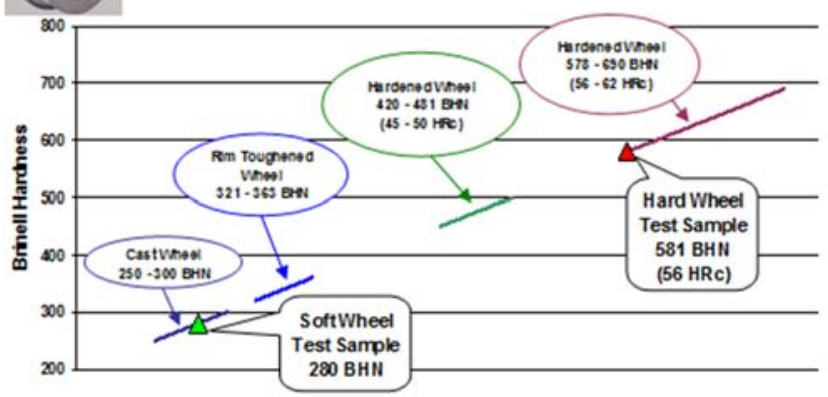

Materials AISI 1055, 1070, 4140

Rim Toughened based on ASTM A504 Class C

Figura 6 - Selecao de materiais de rodas
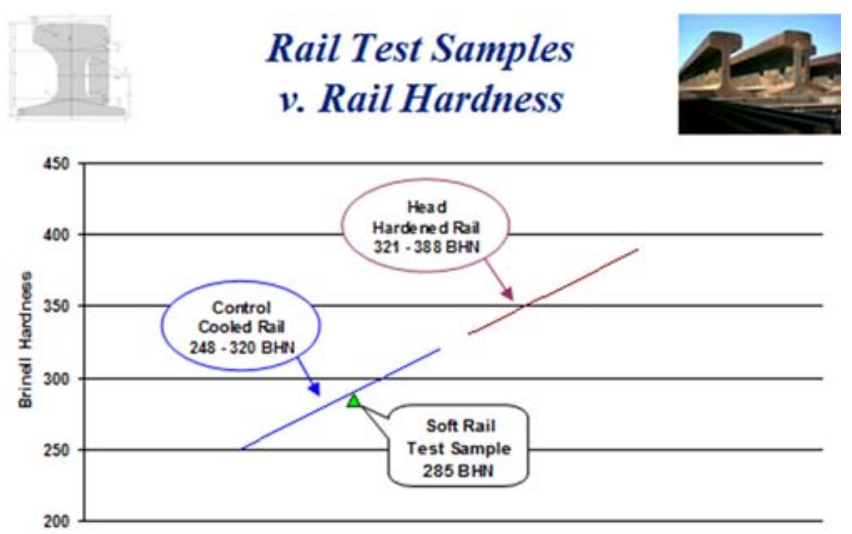

Material based on ASTM A759

Carbon $0.67 \%-0.84 \%$

Figura 7 - Selecao de material de trilho

\section{Material Test Parameters}

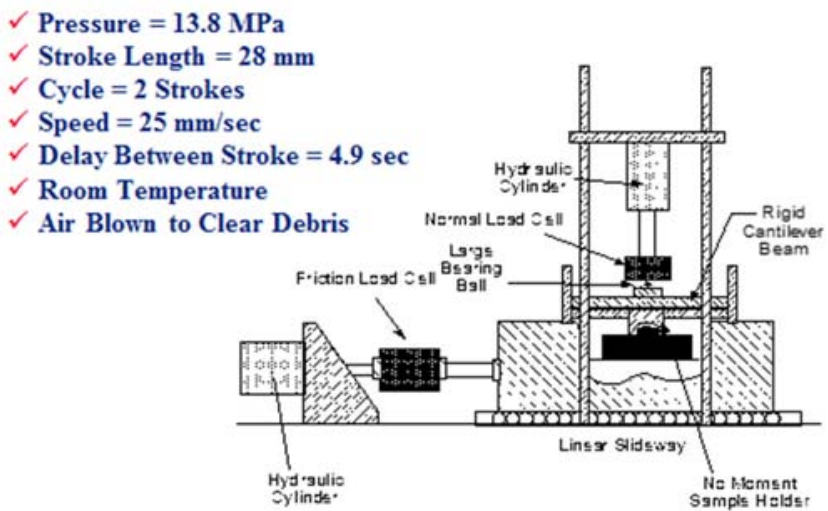

Figura 8 - Equipamento laboratorial para avaliacao de desgaste 
Material Test Samples after 10,000 Cycles

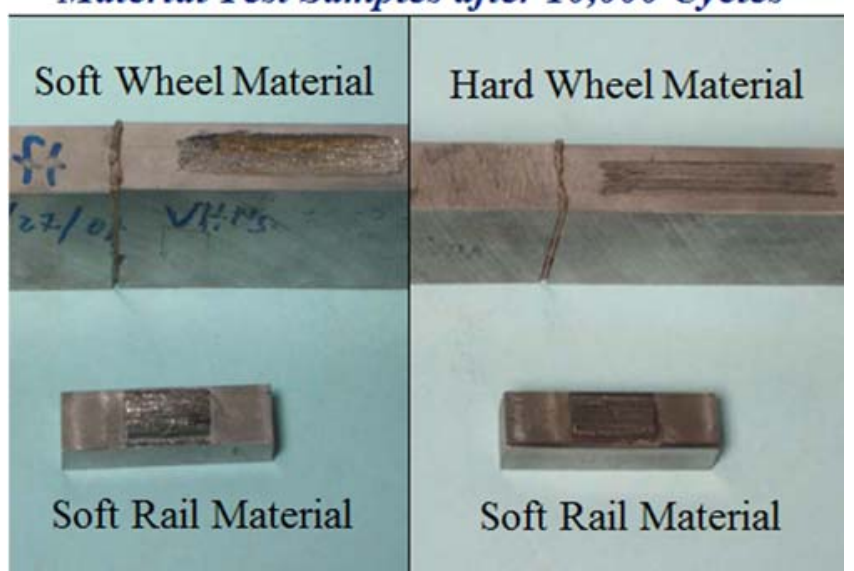

Figura 9 - Desgaste em corpos de prova de rodas e trilhos

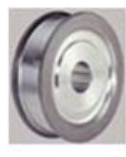

\section{Wheel Wear}

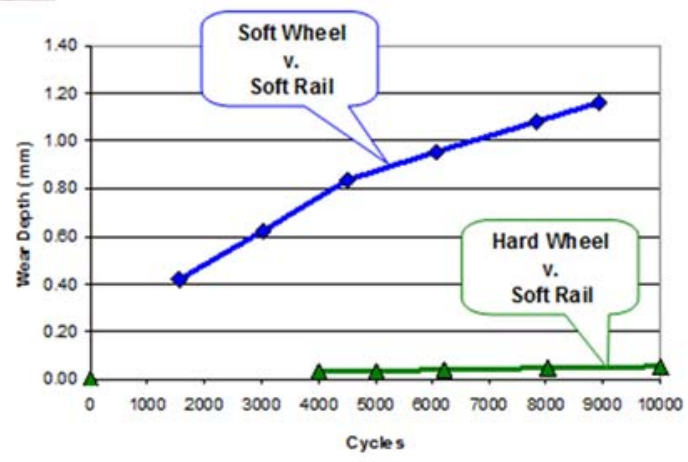

Figura 10 - Medicao do desgaste das rodas
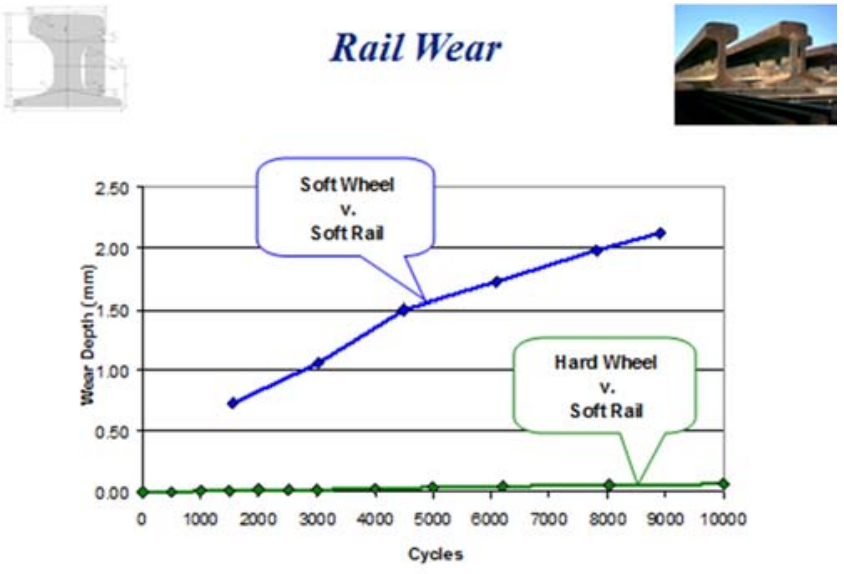

Figura 11 - Medicao do desgaste dos trilhos 
Wear Depth Test Results 10,000 Cycles

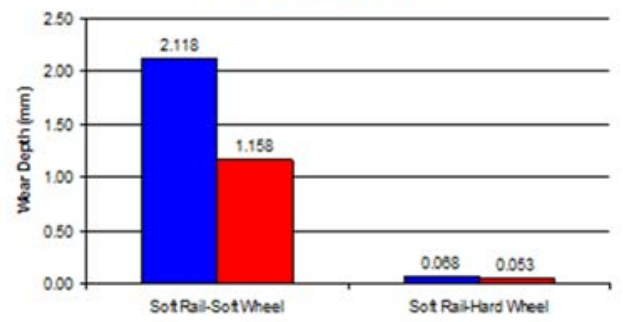

- Rail Wear a WheelWear

$>$ Worst combination for wear is Soft Wheel - Soft Rail

$>$ Best combination for wear is Hard Wheel-Soft Rail

Figura 12 - Desgaste comparativo para rodas e trilhos.

\section{Comparison of Heat Treatments}

Hardness Depths at Middle of Ranges

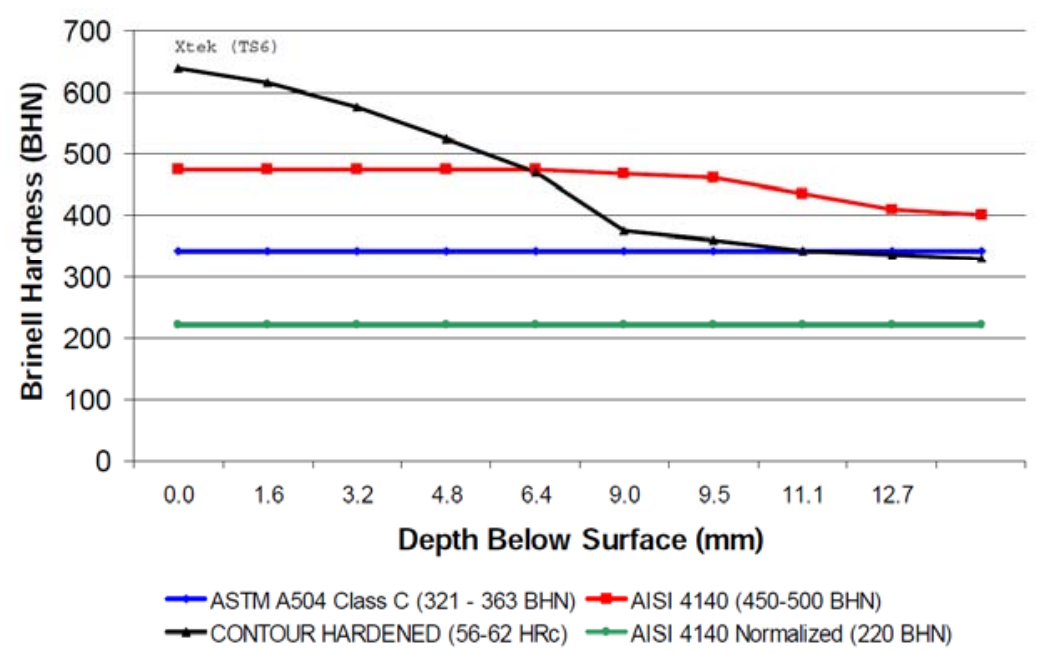

Figura 13 - Materiais e profundidades de dureza em rodas industriais

\section{REFERÊNCIAS}

1 Boletim da InfoMet, www.infomet.com.br, preço de usina, base marco-2015.

2 AIST - Association for Iron \& Steel Tecnology, www.aist.org, medição de coeficientes de atrito, 2000. 